\title{
Isolated primary osteoma cutis of the head: Case report
}

\author{
Natalia Alinda Montecinos Ayaviri ${ }^{1}$ MD, Fábio Xerfan Nahas MD PhD², Marcus Vinícius Jardini Barbosa MD², \\ Andréia Bufoni Farah $M^{2}$, José de Arimatéia Mendes $M D^{1}$, Lydia Masako Ferreira MD PhD²
}

\begin{abstract}
NA Montecinos Ayaviri, FX Nahas, MV Jardini Barbosa, AB Farah, J de Arimatéia Mendes, LM Ferreira. Isolated primary osteoma cutis of the head: Case report. Can J Plast Surg 2006;14(1):33-36.
\end{abstract}

\begin{abstract}
Osteoma cutis is a rare disease in which there is formation of bony tissue in the skin that causes deformities. The etiology remains unknown and its treatment is controversial. A rare case of primary osteoma cutis in the face and scalp, which was not associated with any syndrome, is described. The patient was treated with surgery and topical retinoic acid. The retinoic acid treatment resulted in an improvement of the frontal area, and stabilized the disease over a two-year follow-up period. Surgical resection was a simple treatment with a quick recovery, minimal scarring and no local recurrence. The patient was followed for two years and presented a satisfactory result. The treatment of osteoma cutis is quite variable, and surgery is the most frequently reported treatment. However, a combination of clinical and surgical treatments seems to be an efficient way to manage these patients.
\end{abstract}

Key Words: Calcinosis; Calcium; Calcium metabolism disorders; Dermis; Osteoma steoma cutis is a benign rare disease characterized by the presence of osseous nodules in the reticular layer of the skin (1). The nodules are composed of lamellar bone with osteocytes in the centre and osteoclasts in the external area (2). The etiology of this osseous deposit is still unknown (3).

The first case of osteoma cutis was described in 1858 by Wilckets (4). After that, approximately 50 cases of osteoma cutis were reported in the literature (4). In spite of the benign evolution, the disease may lead to significant cutaneous deformities at the affected areas, causing aesthetic deformities and psychological consequences in the patients.

The highest incidence occurs among female patients, between the second and the third decades of their lives $(3,5)$. The disease is classified as primary or secondary. Primary osteoma cutis (POC) does not present any predisposition or break out factor, whereas secondary osteoma cutis (SOC) is considered to be a result of cutaneous and metabolic alterations, due to an increase of the serum calcium level, and of the thyroid and parathyroid hormones $(1,6-8)$.

The ideal treatment is still not well established, and it may be clinical, surgical or both. Patients with osteoma cutis may be clinically treated with the use of topical and systemic drugs.

\section{Osteoma cutis primaire isolé à la tête : Rapport de cas}

\begin{abstract}
L'osteoma cutis est une maladie rare caractérisée par la formation de tissu osseux dans la peau et provoquant des difformités. L'étiologie demeure inconnue et son traitement est controversé. On décrit ici un cas rare d'osteoma cutis primaire affectant le visage et le cuir chevelu et qui n'était associé à aucun autre syndrome. La patiente a bénéficié d'un traitement chirurgical et d'un traitement par acide rétinoïque topique. Le traitement par acide rétinoïque a donné de bons résultats au niveau du front et a stabilisé la maladie pendant les deux ans qui ont suivi. La résection chirurgicale a été relativement simple et la patiente a récupéré rapidement, avec une cicatrice discrète, et on n'a eu à déplorer aucune récurrence localisée. La patiente a été suivie pendant une période de deux ans et a obtenu des résultats jugés satisfaisants.

Le traitement de l'osteoma cutis peut varier considérablement, la chirurgie étant toutefois la modalité la plus souvent rapportée. Par contre, un traitement clinique et chirurgical mixte semble donner de bons résultats dans la prise en charge de tels patients.
\end{abstract}

Procedures such as curettage, dermabrasion, laser or resection of the lesions are surgical options that can be used to treat this condition.

The present report describes a case of isolated POC located at the face and scalp.

\section{CASE PRESENTATION}

A 20-year-old white woman complained of numerous lesions in the upper one-third of the forehead and in the scalp (Figure 1), which appeared four years before the plastic surgery consultation. The major complaints were local itching, increase in the number of lesions in the past few months and poor cosmetic appearance. The patient denied any history of local trauma or acne vulgaris and the previous endocrine evaluation did not show any hormone alterations.

The lesions were nodular, ranging from $1.0 \mathrm{~mm}$ to $5.0 \mathrm{~mm}$ in diameter, and were located at the parietal region and at the upper one-third of the right side of the forehead. The affected area was approximately $6 \mathrm{~cm} \times 8 \mathrm{~cm}$. The lesions were whitish, hardened, fixed and were not painful to touch.

One of the nodules was biopsied and osteoma cutis was diagnosed. Calcium serum and parathyroid hormone were

${ }^{1}$ Plastic Surgery Residency Program, Instituto Brasileiro de Cirurgia Plástica; ${ }^{2}$ Division of Plastic Surgery of the Federal University of São Paulo, São Paulo, Brazil

Correspondence: Dr Marcus Vinícius Jardini Barbosa, Rua Napoleão de Barros, 715, 4 Andar, Vila Clementino, São Paulo, Brazil.

Telephone and fax 55-11-5576-4118, e-mail drmbarbosa@ig.com.br 

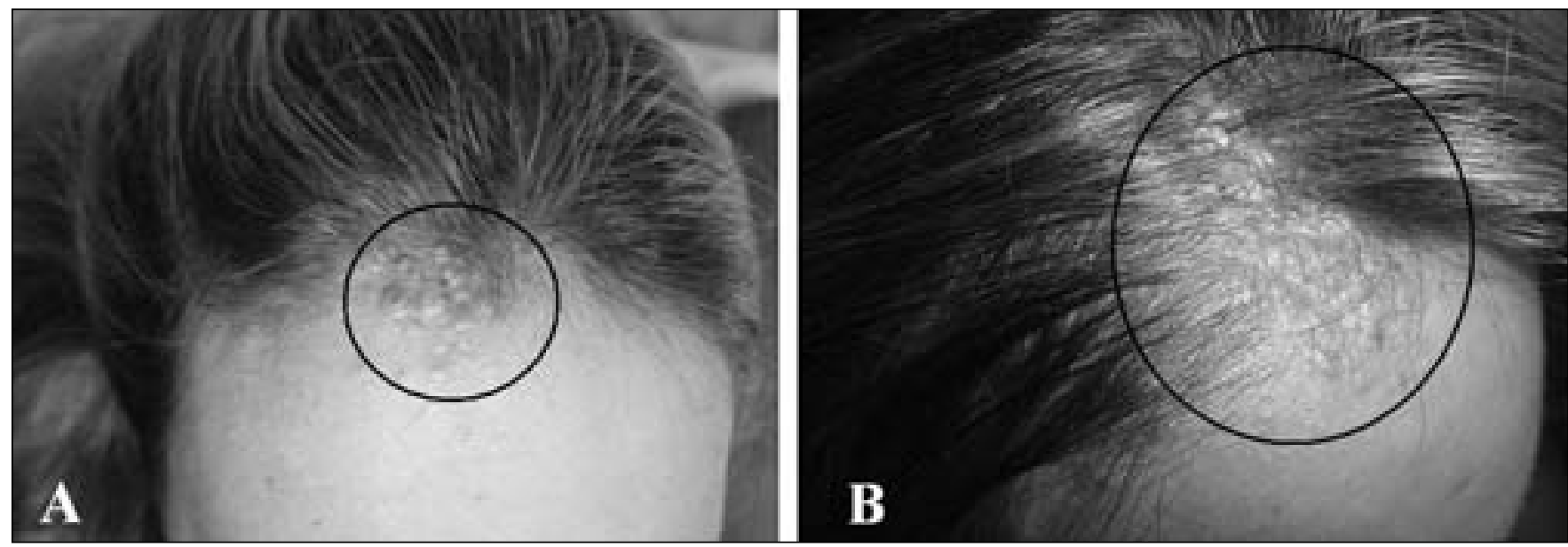

Figure 1) Preoperative aspect. A Lesions in the upper one-third of the forehead; B Lesions in the scalp

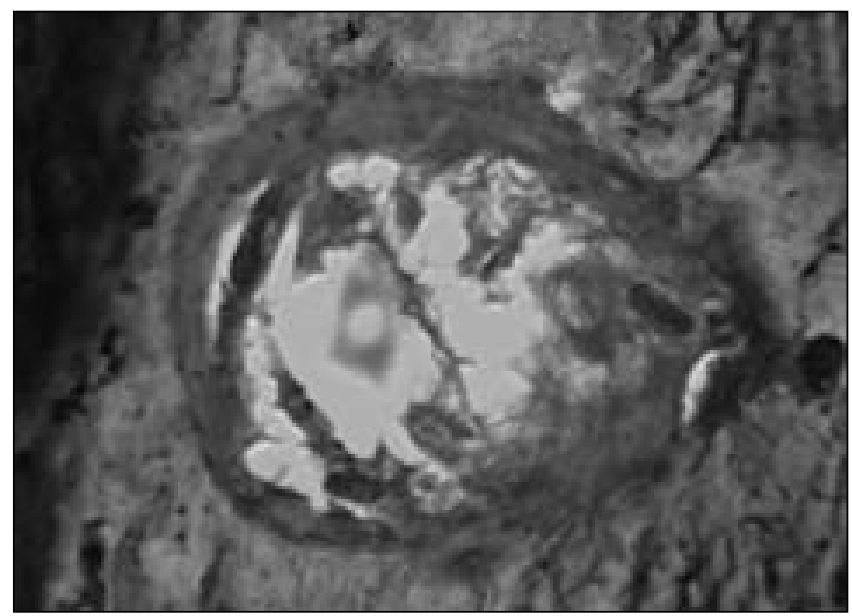

Figure 2) Actual bone formation within the dermis (hematoxylin and eosin stain, original magnification $\times 100$ )

within the normal concentrations. Bone was not detected by radiological examinations.

The wide resection of the lesions using a local flap to cover the area or the use of skin expander were suggested to the patient; however, she did not want to undergo a treatment that would result in extensive scarring.

Partial resection was indicated for the scalp lesions. The surgical specimen was submitted for a histology examination and the diagnosis of osteoma cutis was confirmed by the findings of actual bone formation (Figure 2). The postoperative course was uneventful, but three months after the surgery a partial recurrence occurred. A second resection was performed and the treated area was free of disease after a two-year follow-up period.

To minimize scars on the frontal area, this region was treated clinically with a topical retinoic acid solution, in a $0.015 \%$ concentration, for three months. After that period, the concentration of the acid was increased to $0.025 \%$ and was used for three more months.

There were no new lesions, and those that were treated with retinoic acid decreased in size, with improvement of the cosmetic aspect of the frontal area (Figure 3).

The patient is still being followed, and since the initial treatment of the lesions there has been no increase in size and number. No new areas have been affected.

\section{DISCUSSION}

Osteoma cutis is a benign dermatopathy caused by the deposition of bony nodules in the dermis, which occurs more frequently in women (6). It is classified as primary or secondary (9). POC occurs in $15 \%$ of patients, and it is not related to any history of local trauma or former cutaneous disease (7). It may occur in isolation or in association with a syndrome. The four main syndromes that are associated to the POC are Albright hereditary osteodystrophy, fibrodysplasia of progressive ossification, osseous progressive heteroplasia and platelike osteoma cutis $(5,9)$. Each syndrome presents a specific phenotype with a metabolic dysfunction, which usually occurs in the first years of life. Osteoma cutis may be the first clinical sign of these syndromes (1). Most cases of POC are associated with these syndromes. However, it is possible that POC is involved with other syndromes. Davis et al (8) reported a case of osteoma cutis associated with ossification of the intervertebral space and disks, facial hypoplasia and anomalous dentition. These authors classified this disease as a new syndrome due to the association of osteoma cutis and the dysmorphology of skull and face.

SOC is the most common variant, responsible for $85 \%$ of cases. It is described as a sequela of diseases such as scleroderma, pilomatricoma (Maherbe's calcifying epithelioma), nevi, dematomyositis, basal cell carcinoma, scars, cutaneous inflammation, trauma, venous stasis, syringoma and epidermoid cysts $(5,7)$. However, it is more usually found in patients with a history of acne vulgaris (6).

The patient described in the present study presented with lesions in the scalp and face, with no previous cutaneous lesions and with normal blood tests. It was diagnosed as isolated POC, a very rare condition according to the literature (7-9).

Osteoma cutis presents some variants. The classic multiple miliary osteoma cutis is a variant that affects young women with a history of acne (3), whereas the primary multiple miliary osteoma cutis occurs in elderly women who do not present history of acne vulgaris or inflammatory dermatosis (5). The reason why most cases of osteoma cutis occur in the female sex is still unknown (6).

The most affected areas are the scalp, face, chest, breast, extremities and buttocks (9). The lesions usually do not cause pain or any other symptoms (10). They arise as single or multiple papules, nodules or plaques, or as miliary lesions. 

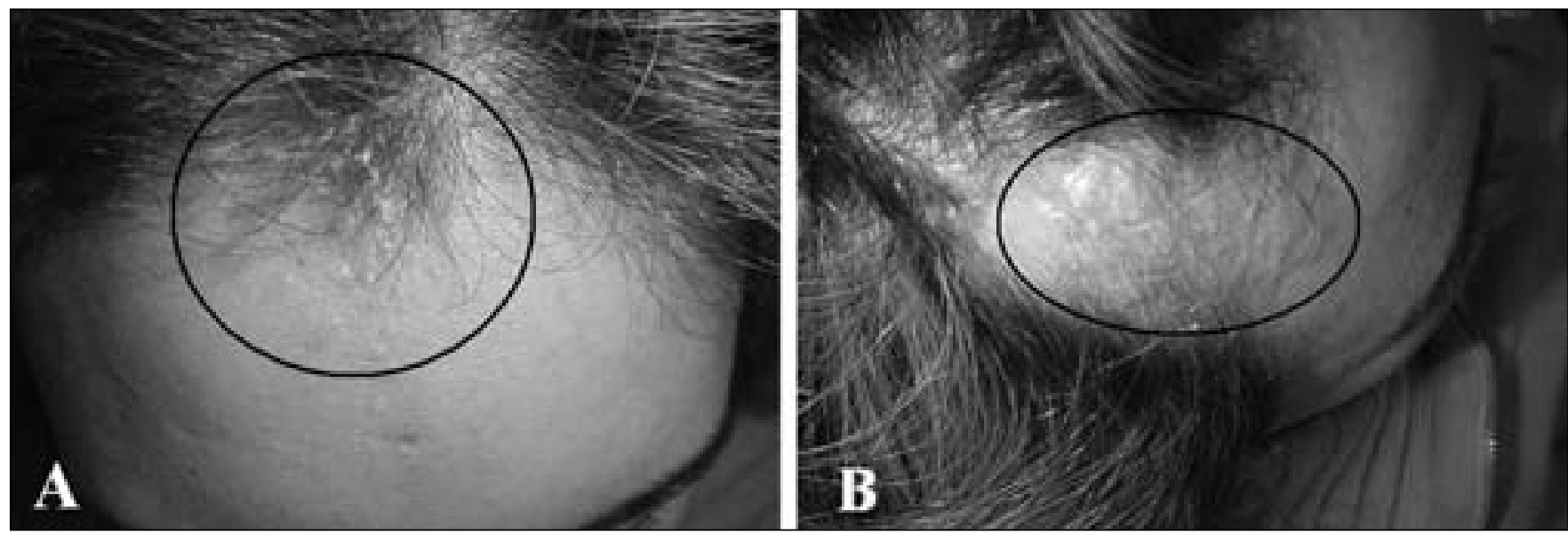

Figure 3) Postoperative aspect after two-year follow-up. A Frontal area; B Scalp area

The pathogenesis of POC is still unknown. Burgdorf and Nasemann (11) reported two theories. The first is based on the anomalous migration of osteoblasts to the skin. The second and more accepted theory is based on the metaplasis of fibroblasts to osteoblasts.

Cottoni et al (7) described the histological evaluation of the lesions as lamellar bone, completely calcified and inhabited by osteocytes (macrocalcification), which occupies the deepest layer of the skin (reticular layer). On electron microscope analysis, the cells demonstrate elongated nuclei, vesicles of rough endoplasmic reticulum and mitochondria, and scanty intramitochondrial granular electron-opaque depositions of calcium. The area around the nodules is less calcified and presents a metaplasis area of fibroblasts to osteoblasts, confirming the aforementioned theory. In the present study, the ultrastructural evaluation of the lesions led to the conclusion that the nodules were true osseous formations.

Baginski and Arpey (3) reported the fibroblast's capacity to differentiate into osteoblasts by the hybridization of dermal fibroblasts in vitro. The fibroblasts showed an active synthesis of type I collagen and osteonectin, both of which are properties of active osteoblasts. Another indicator of bony formation was the high level of alkaline phosphatase and tumour growth factor-beta in the osteoblasts. Another possible etiology of heterotopic ossification is the mutations of the gene GNAS 1, as observed in patients with Albright hereditary osteodystrophy or severe progressive heterotopic ossification within skeletal muscle and deep connective tissue. However, previous reports (8) of POC have not demonstrated this relationship.

The diagnosis may be suspected by the clinical history and physical examination; however, definitive diagnosis is obtained with the histopathology study of the cutaneous lesion (9), as performed in the patient reported in the present study.

Treatment may be clinical, surgical or a combination of both. Topical drugs, such as retinoic acid, should act on the reticular layer of the dermis to achieve good result. Bowman and Lesher (5) described the use of adapalene gel daily after the removal of the osseous fragments through punch biopsy in the face and scalp, but on follow-up the patients had developed skin hyperpigmentation. Moritz and Elewski (2) described the use of retinoic acid to stimulate de-epithelialization, helping the spontaneous elimination of the more superficial osseous fragments.
Etidronate disodium is a drug that inhibits calcium reabsorption, affecting the bone metabolism. Based on these principles, Goldminz and Greenberg (10) used the systemic treatment with this drug orally, in the dose of $11 \mathrm{mg} / \mathrm{kg}$ to $15 \mathrm{mg} / \mathrm{kg}$, in a patient over five months in an effort to inhibit the formation of bony nodules. The patient presented a reduction of the systemic reabsorption of calcium; however, a decrease of anomalous dermal osseous synthesis was not observed.

Surgical treatment is the most frequently used because it reduces the number of lesions (5). It may be performed using total or partial resection, curettage with primary suture, laser or dermabrasion of the affected area (3).

Altman et al (6) used small incisions and curettage to remove facial lesions with minimal local trauma. Primary closure of lesions allowed quick recovery and small scars. Postoperative hyperpigmentation was a common but temporary complication. Baginski and Arpey (3) reported the treatment of facial lesions using curettage associated with a carbon dioxide laser. The hypopigmentation of the treated areas was the most common adverse effect, but the authors reported a good cosmetic result at the long-term follow-up.

Wilhelmsen and Bereston (4) reported good results after the use of dermabrasion to treat facial lesions, with no recurrence of osteoma cutis.

The treatment of osteoma cutis is quite variable, and surgical treatment is the most frequent reported. In the present study, one rare case of isolated (not associated with any syndrome) POC was presented. The present patient was treated with a combination of clinical and surgical procedures. Topical treatment with retinoic acid $(0.015 \%$ and $0.025 \%)$ resulted in an improvement of the frontal area, and also resulted in stability of the disease for a two-year follow-up period. Surgical resection was a simple treatment with a quick recovery, minimal scarring and no local recurrence. Although in the areas of large resection there is a possibility of recurrence, this complication was not observed on a long-term follow-up.

The large treatment variety demonstrates that there is not an ideal procedure and shows how difficult it is to adequately treat this condition. However, a combination of clinical and surgical treatments may be an effective way to manage these patients.

ACKNOWLEDGEMENTS: The authors thank Maisa Cristina Dante da Silveira and Maria Claudia Jardini Barbosa for the English language revision. 


\section{REFERENCES}

1. Mast AM, Hansen R. Multiple papules on the elbows. Congenital osteoma cutis. Arch Dermatol 1997;133:777,780.

2. Moritz DL, Elewski B. Pigmented postacne osteoma cutis in a patient treated with minocycline: Report and review of the literature. J Am Acad Dermatol 1991;24:851-3.

3. Baginski DJ, Arpey CJ. Management of multiple miliary osteoma cutis. Dermatol Surg 1999;25:233-5.

4. Wilhelmsen HR, Bereston ES. Treatment of osteoma cutis. Cutis 1984;33:481,483.

5. Bowman PH, Lesher JL Jr. Primary multiple miliary osteoma cutis and exogenous ochronosis. Cutis 2001;68:103-6.

6. Altman JF, Nehal KS, Busam K, Halpern AC. Treatment of primary miliary osteoma cutis incision, curettage, and primary closure. J Am Acad Dermatol 2001;44:96-9.
7. Cottoni F, Dell' Orbo C, Quacci D, Tedde G. Primary osteoma cutis. Clinical, morphological, and ultrastructural study.

Am J Dermtopathol 1993;15:77-80.

8. Davis MD, Pittelkow MR, Lindor NM, Lundstrom CE, Fitzpatrick LA. Progressive extensive osteoma cutis associated with dysmorphic features: A new syndrome? Case report and review of the literature. Br J Dermatol 2002;146:1075-80.

9. Boschert MT, Puckett CL. Osteoma cutis of the hand. Plast Reconstr Surg 2000;105:1017-8.

10. Goldminz D, Greenberg RD. Multiple miliary osteoma cutis. J Am Acad Dermatol 1991;24:878-81.

11. Burgdorf W, Nasemann T. Cutaneous osteomas: A clinical and histopathologic review. Arch Dermatol Res 1977;260:121-35. 